\title{
Correction to: Buddhist Meditation as a Mystical Practice
}

\author{
Hans Julius Schneider ${ }^{1}$
}

Published online: 20 December 2017

(C) Springer Science+Business Media B.V., part of Springer Nature 2017

\section{Correction to: Philosophia (2017) 45:773-787 https://doi.org/10.1007/s11406-016-9783-y}

The paper was written for and planned to be published within the present collection of papers on Mood. Due to an editorial error, it has been published in Philosophia 45:2 (2017) 773-787 rather than here.

We apologize to the author, Prof. Dr. H. J. Schneider, and to the editors of the present collection, Prof. Dr. A. Ben-Ze'ev and Prof. Dr. A. Krebs, for any inconvenience caused.

The abstract of the paper, the keywords and its first paragraph appear in the sequel.

The paper can be read at https://link.springer.com/article/10.1007/s11406-016-9783-y with Open Access.

Abstract On the basis of many years of personal experience the paper describes Buddhist meditation (Zazen, Vipassanā) as a mystical practice. After a short discussion of the role of some central concepts (longing, suffering, and love) in Buddhism, William James' concept of religious experience is used to explain the goal of meditators as the achievement of a special kind of an experience of this kind. Systematically, its

The online version of the original article can be found at https://doi.org/10.1007/s11406-016-9783-y

\section{Hans Julius Schneider}

Hans.Schneider@uni-potsdam.de

1 Department of Philosophy, University of Potsdam, Potsdam, Germany 
main point is to explain the difference between (on the one hand) a craving for pleasant 'mental events' in the sense of short-term moods, and (on the other) the long-term project of achieving a deep change in one's attitude to life as a whole, a change that allows the acceptance of suffering and death. The last part argues that there is no reason to call the discussed practice irrational in a negative sense. Changes of attitude of the discussed kind cannot be brought about by argument alone. Therefore, a considered use of age-old practices like meditation should be seen as an addition, not as an undermining of reason.

Keywords Experience $\cdot$ Mood $\cdot$ Meditation $\cdot$ Mysticism $\cdot$ William James $\cdot$ Rationality

\section{Introduction}

When approaching a subject matter like the one to be discussed here, it seems appropriate to begin with a few personal words about the background of the author. So the reader should know that I am on the one hand a philosopher working in the fields of Epistemology, Philosophy of Language, and Philosophy of Science. Therefore, I cannot help but use my critical and (at times) skeptical mind when I approach the topic of Mysticism. On the other hand I have by now been practicing Buddhist meditation for about 25 years, with constant sympathy, and I have never seen any tension between these two activities, the critical and the practical. They can live peacefully next to each other. 